Revista do Programa de Pós-Graduação em Mídia e Cotidiano Artigo Seção Livre

Número 6. Volume 6 /Julho 2015

(C) 2015 by UFF

\title{
OS CRITÉRIOS DE NOTICIABILIDADE E A FUNCÃO SOCIAL DA IMPRENSA NOS LIVROS DE HARRY POTTER ${ }^{1}$
}

\section{THE NEWSWORTHINESS CRITERIA AND THE SOCIAL FUNCTION OF THE PRESS IN THE HARRY POTTER BOOKS}

\author{
Gabriela Gruszynski SANSEVERINO²; Gisele Dotto REGINATO ${ }^{3}$; Marcia BENETTI $^{4}$
}

Resumo: Este trabalho analisa os critérios de noticiabilidade e a função social da imprensa na série de livros de J.K Rowling, Harry Potter. Para tanto, mapeamos os critérios de noticiabilidade utilizados pelo jornalismo, identificamos personagens e instituições que exercem papéis ligados à imprensa e compreendemos o papel social exercido pela imprensa. O método utilizado foi a análise de conteúdo. Encontramos oito grupos de critérios contemplados na série: importância; emoção, suspense ou entretenimento; excepcionalidade; conflito ou controvérsia; negatividade; atualidade ou ineditismo; proximidade; interesse público. Sistematizamos três papéis sociais assumidos pela imprensa: informar o que está acontecendo no cotidiano, ditar os assuntos que as pessoas vão falar e conferir credibilidade e prestígio para pessoas, objetos e instituições.

Palavras-chave: Jornalismo; critérios de noticiabilidade; função social; imprensa; Harry Potter.

\footnotetext{
${ }^{1}$ A pesquisa que embasa este artigo foi realizada como Trabalho de Conclusão de Curso de Comunicação Social - Jornalismo da UFRGS, intitulada "Os critérios de noticiabilidade e a função social da imprensa nos livros do Harry Potter”. Disponível em: <http:/hdl.handle.net/10183/88492>.

${ }^{2}$ Mestranda do Programa de Pós Graduação em Comunicação e Informação da Universidade Federal do Rio Grande do Sul - UFRGS. Bolsista Capes. Formada em Comunicação Social - Jornalismo pela UFRGS. Email: gabigrusan@ gmail.com.

${ }^{3}$ Doutoranda do Programa de Pós Graduação em Comunicação e Informação da Universidade Federal do Rio Grande do Sul - UFRGS. Mestre em Comunicação pela Universidade Federal de Santa Maria UFSM. Membro do Núcleo de Pesquisa em Jornalismo- UFRGS/CNPq. Email: giselereginato@ gmail.

${ }^{4}$ Doutora em Comunicação pela PUC-SP, professora do Programa de Pós-Graduação em Comunicação e Informação da Universidade Federal do Rio Grande do Sul - UFRGS. Líder do Núcleo de Pesquisa em Jornalismo - UFRGS/CNPq. Pesquisadora do CNPq. E-mail: marcia.benetti@ gmail.com
} 
Abstract: This paper analyses the newsworthiness and the social function of the press in J.K. Rowling's book series Harry Potter. It maps the newsworthiness criteria used by the press, identifies the characters and institutions that exercise roles linked to journalism and comprehends the social function executed by the press. The method utilized was content analysis. Eight groups of newsworthiness criteria were found in the series: importance; thrill, suspense or entertainment; exceptionality; conflict or controversy; negativity; timelessness or originality; proximity; public interest. Three social functions assumed by the press were systematized: inform what's happening in the everyday life, dictate what people will talk about and confer credibility and prestige to people, objects and institutions.

Keywords: Journalism; newsworthiness criteria; social function; press; Harry Potter.

\section{INTRODUÇÃO}

Harry Potter, como um dos principais fenômenos culturais do século XXI, permite uma reflexão sobre a constituição e as rotinas da imprensa a partir das teorias do jornalismo. A representação que J.K. Rowling cria do jornalismo em seus livros não apenas capta diversos elementos do que acontece na imprensa mundial, como também auxilia na construção da percepção que os seus leitores terão do jornalismo.

A mímese entre os personagens criados por Rowling e suas estruturas correspondentes no mundo não-ficcional permitem que teorias desenvolvidas para estudar o jornalismo possam ser utilizadas como referências para refletirmos sobre a construção da imprensa na série dos livros do Harry Potter. Sendo assim, o objetivo deste artigo é analisar os critérios de noticiabilidade e a função social da imprensa nos livros do Harry Potter.

\section{O jornalismo como conhecimento sobre o mundo}

"O homem sempre precisou de alguma forma de mediação para conhecer a realidade" (MOTTA, 2002, p. 2). Hoje, de acordo com Motta (2002), a sociedade é mediada pelos mass media, que proporcionam para as pessoas boa parte do 


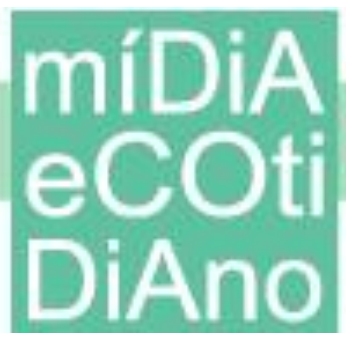

conhecimento que estas adquirem sobre o mundo. As notícias ajudam a sociedade a selecionar, priorizar, compreender e organizar os acontecimentos de sua realidade.

O acontecimento, no discurso jornalístico dos media, passa a ser central, constituindo "o referente do qual se fala, o efeito de realidade da cadeia dos signos, uma espécie de ponto zero da significação" (RODRIGUES, 1993, p. 27). Esse acontecimento jornalístico irá se diferir dos tantos outros que ocorrem no mundo "em função de dados mais ou menos objetivos na relação com o tempo, o espaço e a hierarquia que convertem o acontecimento em notícia" (CHARAUDEAU, 2007, p. 133, grifos do autor).

Motta (2002) pensa a notícia como dotada de um significado, na maioria das vezes, surpreendente, que relata acontecimentos que rompem com aquilo que é esperado. As notícias existem apenas quando há percepção de algo que foge da rotina: "um conteúdo novo e surpreendente que chega, via meios de comunicação (jornais, revistas, emissoras de rádio e televisão e rede), até as rotinas de significações do mundo da vida cotidiana dos indivíduos nas sociedades modernas" (MOTTA, 2002, p. 3).

O jornalismo que temos hoje, desenvolvido em uma sociedade democrática, teve suas raízes no século XIX, quando, com a expansão dos jornais, um número maior de pessoas passou a se dedicar exclusivamente à atividade que visava fornecer informações. Neste contexto, surgem os valores que são, até hoje, identificados como jornalismo: "as notícias, a procura da verdade, a independência dos jornalistas, a exatidão, e a noção do jornalismo como um serviço público [...]” (TRAQUINA, 2008, p. 34).

Dois processos marcaram a evolução da atividade jornalística. O primeiro foi a comercialização desta atividade, enquanto o segundo foi a profissionalização de seus trabalhadores. Os jornalistas, reconhecidos como profissionais, têm uma competência específica: o fornecimento de informação à sociedade, isto é, o fornecimento de notícias (TRAQUINA, 2008). A função de informar pode ser compreendida como "a transmissão de um saber, com a ajuda de uma determinada linguagem, por alguém que o possui a alguém que se presume não possuí-lo" (CHARAUDEAU, 2007, p. 33). As notícias são o valor absoluto da cultura jornalística e os repórteres foram "se 


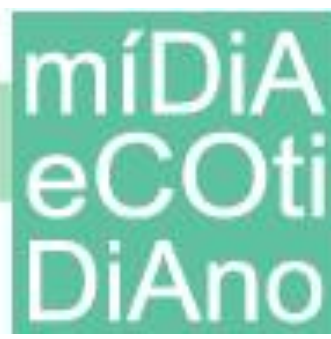

transformando num mito coletivo no qual representam o indivíduo na sociedade de massas, aptos a mobilizar o poder da imprensa para corrigir a injustiça” (TRAQUINA, 2008, p.60).

No contrato de comunicação que estabelece o jornalismo como um gênero discursivo (BENETTI, 2008), a representação do jornalista sobre si mesmo - e sobre o jornalismo que diz exercer - coordena parte da imagem que lhe será atribuída depois pelo leitor. Tais representações constroem o ethos jornalístico, "um conjunto de disposições, percepções e valorações que jornalistas têm de si e do mundo, uma dimensão do habitus que contém a autoimagem e, nesse sentido, orienta as representações" (LAGO, 2003, p. 2, grifo da autora).

\section{A função social do jornalismo}

Desde o início da história das civilizações teve-se o interesse de saber o que há de novo. As notícias, mesmo antes de assumirem este formato que conhecemos na contemporaneidade, eram consumidas pela sociedade em resposta ao seu desejo de estar informada. Como apontam Kovach e Rosenstiel, "precisamos de notícias para vivermos, para nos protegermos, para criarmos laços, para identificarmos amigos e inimigos. $\mathrm{O}$ jornalismo é, simplesmente, o sistema concebido pelas sociedades para fornecer estas notícias" (2004, p. 6).

Nossas vidas cotidianas, de acordo com Miguel (1999), nos colocam em contato apenas com uma pequena parcela de informações de que podemos precisar. Os fatos dos quais tomamos conhecimento de forma independente da imprensa são muito restritos. Assim se justificaria a existência do jornalismo: necessitamos de um veículo especializado na transmissão de informações.

Com o surgimento do sistema de impressão, tiveram-se as condições necessárias para a produção de jornais e para a caracterização do jornalismo como uma atividade baseada na coleta e na transmissão de notícias. A profissão, contudo, torna-se mais que um mero ofício ao operar a partir de laços sociais que permitem que o jornalismo se estabeleça como uma instituição. No século XIX, a institucionalização da cultura 


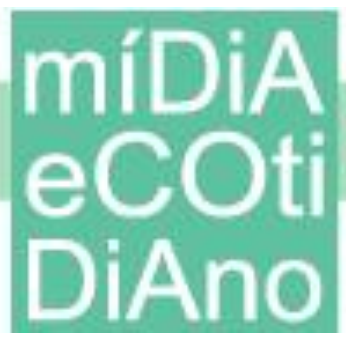

jornalística se dá pela sua gradativa independência de outras instituições e suas normas. Cria-se a base do jornalismo moderno, com valores como a objetividade jornalística e a formação de um mercado de leitores.

Para Traquina, o jornalismo pode ser explicado como a resposta para a pergunta que as pessoas fazem todos os dias: "o que é que aconteceu/está acontecendo no mundo?" (2008, p. 20). As pessoas buscam o jornalismo para ficarem informadas e, assim, conseguirem combinar estas informações com o seu conhecimento dos tópicos, o que lhes permite interagir com os outros e criar sua visão dos fatos.

Gomis (1997) entende que a atividade profissional dos jornalistas consiste em uma interpretação sucessiva da realidade social. As notícias formam a imagem da realidade que o público utiliza para se manter informado: "Os meios atuam como mediadores generalizados. Esta é a sua função social"5 (GOMIS, 1997, p. 175, tradução nossa). Os meios permitem que a realidade social que está sempre mudando seja reduzida a uma imagem cômoda e manejável, a qual o público pode ter acesso ao longo do dia.

A notícia diz respeito à sociedade na qual se insere, ou, como explica Alsina (2009), seu ecossistema. Há acontecimentos que podem ser relevantes no Brasil que não têm a mesma importância no Canadá, por exemplo. Enquanto em cidades brasileiras um urso invadindo as ruas de uma cidade seria chocante, quebraria com quaisquer expectativas, nas cidades do Canadá isso acontece de forma rotineira, pois ursos são naturais da região e os moradores lidam com a presença dos animais em seu cotidiano. O jornalismo só irá cumprir sua função de informar na medida em que respeitar o interesse da sociedade na qual se insere, ou seja, quando noticiar acontecimentos relevantes para aquele ecossistema.

Ao tornar-se uma instituição social, o jornalismo assume determinados compromissos com a sociedade, os quais irão compor sua imagem perante o público. A profissão deve corresponder à expectativa da sociedade por novidades, mesmo que isso signifique que os jornalistas tenham de enfatizar ou privilegiar certos aspectos de um acontecimento para que este ganhe importância em relação a outros. Historicamente, a

\footnotetext{
5 No original: "Los médios actúan de este modo como mediadores generalizados. Esta es su función
} social". 


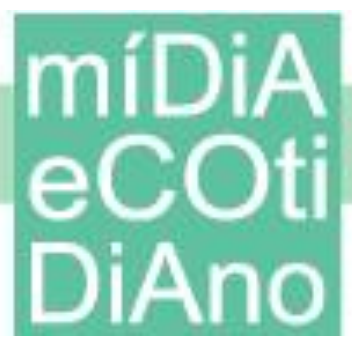

notícia é criada para responder a esta necessidade da sociedade de ter relatos padronizados sobre novas ações, situações, debates e opiniões que se apresentem como relevantes para uma coletividade (FRANCISCATO, 2005).

O jornalismo cresce a partir do "seu papel específico de disseminador de informações sobre a vida cotidiana e fomentador de uma cultura de leitura de publicações impressas" (FRANCISCATO, 2005, p.36), tendo assim maior importância cultural e social onde se insere. Jornalismo e público criam um vínculo que opera com percepções do âmbito da credibilidade, confiabilidade e legitimidade. A profissão tem como alicerce a legitimidade social, a partir da percepção de que é uma prática autorizada a narrar a realidade. Essa legitimidade, contudo, é tanto essencial, como instável: “[...] é cotidianamente colocada em questão quando, a cada edição do jornal ou a veiculação de programa telejornalístico, o indivíduo, ao exercitar a sua condição de cidadão ou de mero consumidor, opta por renovar este vínculo" (FRANCISCATO, 2005, p. 172).

No jornalismo, como coloca Christofoletti, a técnica e a ética têm uma ligação intrínseca: "no jornalismo, a ética é mais que um rótulo, que acessório. No exercício cotidiano da cobertura de fatos que interessam à sociedade, a conduta ética se mistura com a própria qualidade técnica e de produção do trabalho" $(2008$, p. 8). Os meios de comunicação são obrigados à verdade e perderiam sua razão de ser caso abandonassem essa exigência, pois, como explica Cornu (1994), falhariam em sua missão de fornecer às pessoas os elementos necessários para a formação de sua opinião e os instrumentos de compreensão que possibilitam sua colocação na sociedade.

A exigência de verdade na profissão perpassa a observação do acontecimento, a sua interpretação e a sua narração. O jornalista fica responsável por esse processo e deve afirmar as relações de sua narrativa com a realidade a partir do conjunto de operações durante a construção da notícia. O jornalismo tem a capacidade de, através de suas ações, repercutir e amplificar uma informação e isso deve ser sempre considerado pelo jornalista em suas escolhas ao longo do processo de elaboração das notícias. A profissão, como coloca Miguel (1999), é capaz de eleger temas, apresentar os fatos que 


\section{míDiA

considera relevantes para a compreensão de tais temas e ainda estabelecer que valores irão presidir sob a apreciação desta realidade construída:

Os meios de comunicação se ocupam das narrativas cotidianas que tem como protagonistas pessoas de todas as partes, o que significa dizer que o jornalismo lida com reputações e honras pessoais, com valores e conceitos, com o imaginário popular e com o próprio senso de verdade e realidade (CHRISTOFOLETTI, 2008, p. 32).

Deve-se observar que a imprensa tem também um papel na construção do capital simbólico. Ao assumir uma posição de agregador e difusor da informação, o jornalismo consegue cumprir a função de produção de crédito social "que permite a certos indivíduos ocuparem posições de autoridade em determinados campos" (MIGUEL, 1999, p. 201). Figuras públicas têm sua posição ratificada pela imprensa, pois figuram nas notícias por estarem em um lugar de poder e por gerarem acontecimentos que lhes garantam espaço nos meios de comunicação.

Dois polos sustentam o jornalismo: o ideológico, que parte dos profissionais a partir de seu olhar da profissão como um serviço público fundamental para a democracia, e o econômico, estabelecido pelos empresários de comunicação, que o percebem como um negócio, um produto (TRAQUINA 2008). A ética, de acordo com Bucci (2000), é que será capaz de equilibrar estes dois polos ao guiar o profissional para seu dever de dar mais importância à função social do que à comercial do seu trabalho.

Os leitores acompanham as notícias acreditando que elas são um índice do real e que os jornalistas não irão ultrapassar a fronteira entre a realidade e a ficção. Esse acordo tácito entre leitores e jornalistas, de que essa fronteira não será ultrapassada, permite a leitura das notícias como descrições da realidade.

O leitor/ouvinte/espectador, no papel de consumidor de notícias, mantém em relação ao jornalismo uma atitude de confiança [...]: 1) confiança quanto à veracidade das informações relatas; 2) confiança quanto à justeza na seleção e hierarquização dos elementos importantes ao relato; 3) confiança quanto à justeza na seleção e hierarquização das notícias diante do estoque de "fatos" disponíveis (MIGUEL, 1999, p.199, grifo do autor). 
O jornalismo se consolida na "cultura do tempo presente", quando fatores de novidade, originalidade e simultaneidade passam a dar sentidos temporais únicos para as práticas sociais: "viver o presente se torna como que uma obsessão social [...]" (FRANCISCATO, 2005, p. 63).

\section{Os critérios de noticiabilidade}

Com o crescimento do papel do jornalismo na sociedade e sua institucionalização, criou-se uma identidade compartilhada por aqueles que praticavam esta atividade. Os jornalistas, em sua maioria, passam a ter o seu trabalho como principal elemento constituinte de sua identidade. Eles vivem as notícias, a busca da verdade e a defesa do bem comum, seu trabalho é um serviço à população para quem devem levar informações úteis: "Ser jornalista é ser 'mediador' que deixa visível a vida social, o 'pedagogo', e o 'organizador' que põe clareza no caos dos acontecimentos” (NEVEU, 2006, p. 37, grifos do autor).

Os jornalistas são os profissionais que dominam a linguagem específica necessária para elaborar as notícias, são autoridades na área. Sua competência específica será o fornecimento de informações à sociedade. O grupo tem uma forte identidade profissional, um ethos, que define a maneira como se deve ser jornalista e estar no jornalismo. As notícias são o valor absoluto da cultura jornalística e fazem dos jornalistas participantes ativos no processo de construção da realidade, a partir da necessidade de escolher, excluir e acentuar certos aspectos de um acontecimento para transformá-lo no relato que chega ao público.

"Os jornalistas têm óculos particulares - são os seus valores-notícia" (TRAQUINA, 2008, p. 77). Todos os dias os jornalistas enfrentam o desafio de ter que elaborar as notícias que serão divulgadas nos meios de comunicação. Os profissionais têm que julgar, entre os diversos acontecimentos que podem ocorrer em qualquer lugar a qualquer momento, quais irão se tornar notícia. Essa seleção dos acontecimentos e construção destes eventos só consegue ser feita pelos detentores de um conhecimento 


\section{míDiA \\ ecO DiAno}

específico ao jornalismo, isto é, apenas a partir das habilidades que somente os membros dessa comunidade profissional têm.

Os valores-notícia são um aspecto fundamental da cultura jornalística e possibilitam a reflexão sobre a natureza e o objeto das notícias. Wolf (2006) define os valores-notícia como critérios de relevância que são disseminados por todo o processo de produção das notícias, estando presentes tanto na seleção de qual acontecimento se tornará notícia, como nos procedimentos posteriores de redação do texto.

A determinação de que acontecimentos se tornarão notícias se dá através da noticiabilidade. Os valores-notícia compõem esta noticiabilidade e "constituem a resposta à pergunta seguinte: quais os acontecimentos que são considerados suficientemente interessantes, significativos e relevantes para serem transformados em notícias?" (WOLF, 2006, p. 195).

Podemos definir o conceito de noticiabilidade como o conjunto de critérios e operações que fornecem a aptidão de merecer um tratamento jornalístico, isto é, possuir valor como notícia. Assim, os critérios de noticiabilidade são o conjunto de valores-notícia que determinam se um acontecimento, ou assunto, é susceptível de se tornar notícia, isto é, de ser julgado como merecedor de ser transformado em matéria noticiável e, por isso, possuindo "valornotícia" ("newswhorthiness") (TRAQUINA, 2008, p.63, grifos do autor).

Os critérios de noticiabilidade podem ser divididos entre os de seleção e os de construção. Os valores-notícia de seleção se referem àqueles que os jornalistas utilizam para selecionar os acontecimentos que irão se tornar notícia. Eles são divididos em dois subgrupos. Os critérios substantivos, que pensam a avaliação direta do acontecimento de acordo com importância e interesse, incluem a morte, a notoriedade, a proximidade, a relevância, a novidade, a atualidade, a notabilidade, a surpresa, o conflito, a infração e o escândalo. Os critérios contextuais dizem respeito ao contexto de produção da notícia e estão diretamente ligados as rotinas produtivas do jornalismo, abarcando a disponibilidade, a visualidade, o equilíbrio, a concorrência, a exclusividade e o dia noticioso.

Os valores-notícia de construção, qualidades da construção do acontecimento como notícia, funcionam como linhas-guia para a apresentação do fato selecionado, 


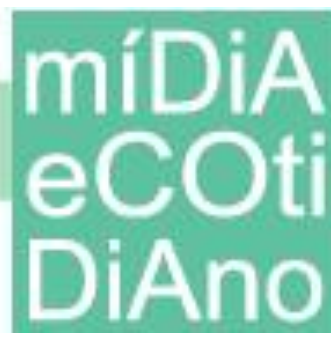

sugerindo o que deve ser destacado, omitido e priorizado na transformação do acontecimento em notícia. Eles são critérios de seleção dos elementos do acontecimento que irão ou não ser incluídos na notícia e incluem a personalização, a dramatização, a simplificação, a ampliação, a relevância e a consonância.

\section{A representação do jornalista na ficção}

Há na ficção, como explica Travancas (2003), duas representações típicas do jornalista: o vilão, que faz tudo para atingir seus objetivos e conseguir um furo de reportagem, e o herói, que tem a profissão acima de qualquer outra coisa e sempre luta pela verdade dos fatos. O jornalista, de acordo com Travancas (2003), tem uma imagem na literatura que é ambígua e contraditória, às vezes fascinando e atraindo e às vezes se mostrando como uma figura inescrupulosa, desonesta e mau caráter. Este profissional tem uma visão de mundo e um estilo de vida que são específicos e acabam refletidos nas obras de literatura que têm o jornalista como personagem. O mundo do jornalista gira em volta das notícias. O jornalista percebe o mundo a partir de uma visão particular determinada pela sua obsessão - e dependência - da notícia.

Quando vilões - a representação mais comum deste profissional -, os jornalistas são apresentados como pessoas sem caráter, que trabalham em uma imprensa que não é necessariamente corrompida, mas é leviana e age apenas de acordo com os seus interesses (TRAVANCAS, 2003). Neste caso, o jornalista também pode aparecer como uma pessoa que valoriza o lugar que tem na sociedade por causa de sua profissão e escreve seus textos sem se preocupar com a veracidade ou a consequência dos fatos. $\mathrm{O}$ mítico "furo" é tratado por Travancas (2003) como a possibilidade que o jornalista tem de diferenciação na profissão, da conquista do reconhecimento.

Mesmo tendo-se duas concepções tradicionais do jornalista na literatura, é possível perceber pela análise de Travancas (2003) que este profissional raramente assume o papel de herói. Os personagens em si não são retratados de forma classicamente heroica, isto é, não são seres idolatrados pela sociedade, ricos, bonitos, etc. Pelo contrário, tendem a aparecer como pessoas solitárias, que não têm nada além 


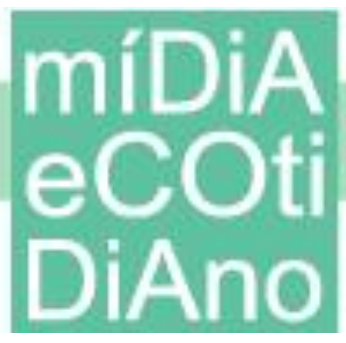

da profissão. Sua obsessão com as notícias segue a permear as obras de ficção, mostrando-se como um profissional que é comprometido com a verdade e tem sua vida inteira centrada no jornalismo. Ele aparece em um contexto de defensor da verdade e do bem comum ao qual a sociedade tem direito, mas não ganha veridicamente um status heroico perante a população. O jornalista se mantém como uma pessoa que não tem nada além da profissão e que faria tudo para conseguir sua grande história.

\section{O mundo mágico de Harry Potter}

Em 1990, sete anos antes de o primeiro livro ser publicado, Rowling ${ }^{6}$ já havia começado a pensar no enredo de Harry Potter, mas foi apenas em 1994 que a história do menino Harry Potter ganhou vida. Christopher Little, ao ler o manuscrito da autora, acreditou no potencial de sua história. $\mathrm{O}$ agente literário enviou originais para diversas editoras, até que a Bloomsbury ${ }^{7}$ decidiu publicar a obra de Rowling.

J.K. Rowling estreou sua série de best sellers com Harry Potter e a Pedra Filosofal (Harry Potter and the Sorcerer's Stone), lançado em 1997. Nos anos seguintes, Rowling teve outros seis livros da série Harry Potter publicados: Harry Potter e a Câmara Secreta (Harry Potter and the Chamber of Secrets - 1998), Harry Potter e o Prisioneiro de Azkaban (Harry Potter and the Prisoner of Azkaban - 1999), Harry Potter e o Cálice de Fogo (Harry Potter and the Goblet of Fire - 2000), Harry Potter e a Ordem da Fênix (Harry Potter and the Order of the Phoenix - 2003), Harry Potter e o Enigma do Príncipe (Harry Potter and the Half Blood Prince - 2005 ) e Harry Potter e as Relíquias da Morte (Harry Potter and the Deathly Hallows - 2007).

O mundo mágico criado pela autora narra a história de Harry Potter, o menino bruxo. Por onze anos ele viveu com seus tios e seu primo Trouxas - pessoas não mágicas, acreditando ter perdido os pais em um trágico acidente de carro. Quando,

\footnotetext{
${ }^{6}$ Joanne Rowling nasceu na cidade de Yate, no interior da Inglaterra, em 31 de julho de 1965. A data indica a grande influência da vida da autora na série de livros que a tornaria milionária: 31 de julho é também o aniversário de Harry, personagem principal de sua famosa série de livros.

${ }^{7}$ Com receio de que meninos tivessem preconceito com um livro escrito por uma mulher, a editora sugeriu que a autora usasse apenas as iniciais ao invés de Joanne. Ela adotou a ideia. Como tinha, porém, apenas um nome próprio, resolveu usar também a letra "K", do nome de sua avó favorita, Kathleen (SMITH, 2003).
} 


\section{míDiA \\ miDi

porém, chega a hora de ingressar em Hogwarts, Escola de Magia e Bruxaria, Harry finalmente descobre a verdade sobre quem é: um herói do mundo mágico. Quando tinha apenas um ano de idade, derrotou o bruxo das trevas, Voldemort, na mesma noite em que este matou seus pais.

Deste momento em diante, passamos a conhecer como funciona este mundo da magia e conseguimos perceber como várias instituições apresentadas nos livros assemelham-se às estruturas existentes na vida não-ficcional. Sua forma de governo, o Ministério da Magia, regula as relações com os Trouxas e os diversos setores da vida dos bruxos, como meios de transporte, relações internacionais e esportes. A imprensa atuante no mundo mágico, representada pelo jornal, pela revista e pelo rádio, também desempenha a função de informar o público.

\section{Os critérios de noticiabilidade na imprensa de Harry Potter}

A metodologia utilizada neste trabalho para pensar sobre os critérios de noticiabilidade e a função social nos livros do Harry Potter foi a análise de conteúdo, definida como "um conjunto de técnicas de análise das comunicações" (BARDIN, 2006, p. 27, grifos da autora), uma análise de significados ou de significantes que se utiliza de procedimentos sistemáticos e objetivos de descrição do conteúdo de mensagens.

Pode-se pensar na análise de conteúdo como uma técnica investigativa que, através de descrições objetivas, sistemáticas e quantitativas do conteúdo exposto, permite interpretar formas de comunicação. Herscovitz (2008) elabora que, com a análise de conteúdo, conseguimos fazer inferências sobre aquilo que ficou impresso ou gravado e permite que possamos detectar tendências e modelos na análise de critérios de noticiabilidade. Bardin (2006) entende que a intenção da análise de conteúdo é esta inferência de conhecimentos que se relacionam com as condições de produção e, às vezes, de recepção.

Rowling inseriu o jornalismo na série Harry Potter através da televisão, do rádio, do jornal impresso e da revista, dando aos personagens e às instituições diferentes níveis 


\section{míDiA \\ miDi

de importância ao longo do desenvolvimento do enredo. O discurso da mídia na narrativa se mostra capaz de influenciar diversas relações que se formam na história e torna-se essencial para o desenvolvimento de uma sociedade - tanto bruxa, quanto Trouxa - que mimetiza a que temos na realidade.

Em Harry Potter, os meios de comunicação são divididos entre os veículos Trouxas e os bruxos. Deve-se observar que ambos apresentam o mesmo formato de jornalismo, tendo como forma de diferenciação os recursos a que cada meio tem acesso - enquanto os bruxos têm a magia, os Trouxas têm a tecnologia. Os veículos que pertencem à comunidade mágica têm um papel mais relevante para o desenrolar da história, mas os meios de comunicação dos Trouxas servem para criar ligações entre as duas realidades, mesmo que estas passem despercebidas pelos personagens. A intersecção entre o mundo dos bruxos e dos Trouxas através da imprensa pode ser observada desde o início da série Harry Potter.

A televisão, inexistente na realidade mágica de Rowling, é o veículo que caracteriza a imprensa Trouxa. Sem nomear um canal específico, através de programas de notícia genéricos, a mídia é inserida na casa dos Dursley. O Profeta Diário é o símbolo da mídia impressa nos livros Harry Potter, sendo mencionado em todos os volumes da série. O jornal tem mais de uma edição diária - manhã e noite, permitindo que mesmo aqueles que têm uma convivência menor com outros bruxos possam manter uma ligação com esta comunidade. Vale notar que, no caso do Profeta Diário, fica claro no desenrolar do enredo de Rowling que o governo, quando forte e estável, consegue influenciar aquilo que é publicado.

A Witch Weekly, revista que aparece em momentos pontuais da história, apresenta-se como uma publicação que discute em grandes reportagens assuntos que ou recebem pouco espaço no jornal, ou nem sequer aparecem no Profeta Diário. Seria o equivalente a uma publicação de fofocas, que tem matérias mais de interesse humano, com personagens e seus dramas pessoais. O Pasquim é inserido na narrativa de Rowling como uma publicação alternativa, em que matérias que não têm espaço na mídia tradicional podem ser divulgadas. Enquanto o Profeta Diário tende a se manter ao lado 


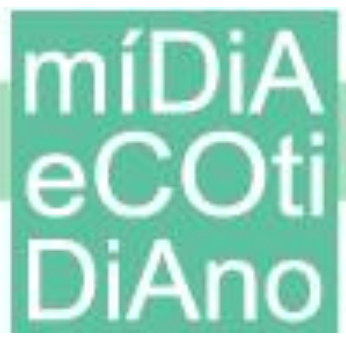

do poder corrente, a revista possibilita que as minorias veiculem a sua versão dos fatos. Os mesmos assuntos podem sair em ambas as publicações, mas com diferentes focos.

Rita Skeeter é a principal jornalista da série, que escreve ao longo da história para todos veículos impressos da comunidade bruxa. Xenophilius Lovegood é dono, editor e repórter da revista $\mathrm{O}$ Pasquim, uma publicação que reflete sua excentricidade. A revista, como podemos inferir a partir da leitura completa da série, é identificada com a personalidade de seu dono. O seu papel se torna essencial no romance não por incorporar características que parecem clássicas do jornalista, mas por viabilizar a abertura de um espaço alternativo para o jornalismo.

Através da análise de conteúdo dos sete livros de J. K. Rowling e da categorização de como a imprensa é retratada nas obras do Harry Potter, é possível estabelecer quais critérios de noticiabilidade permeiam a imprensa construída no enredo. Os valoresnotícia foram divididos em oito grupos com base na categorização construída por Moreira (2006): importância; emoção, suspense ou entretenimento; excepcionalidade; conflito ou controvérsia; negatividade; atualidade ou ineditismo; proximidade; e interesse público. A análise demonstra que todos esses critérios foram contemplados na imprensa criada por J.K. Rowling em Harry Potter.

Todas as aparições da imprensa em Harry Potter foram catalogadas considerando todas as menções de meios de comunicação; todos os personagens que assumiram papéis ligados à imprensa; a fala de personagens sobre notícias, jornalistas ou veículos jornalísticos; e notícias escritas por Rowling como parte da história. A partir desta catalogação é possível observar que o jornalismo está presente em toda a história de Harry Potter, como um espaço de relatos da realidade que explicam o que está acontecendo no mundo dos personagens. Os textos jornalísticos se tornam uma forma dos personagens - e dos leitores - criarem ligações entre as realidades Trouxa e bruxa, entre diferentes acontecimentos e diferentes pessoas.

Encontrou-se 86 casos nos quais os critérios de noticiabilidade permeiam o jornalismo nos sete livros do Harry Potter (Gráfico 1), considerando as notícias criadas pela autora inseridas no enredo e a fala dos próprios personagens sobre informações 


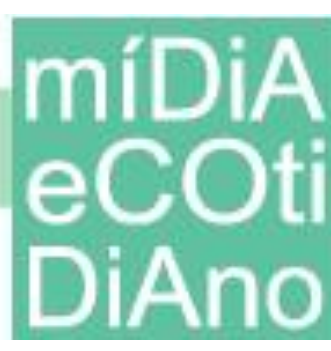

publicadas na imprensa. Deve-se observar que, em uma mesma notícia, é possível encontrar mais de um critério de noticiabilidade.

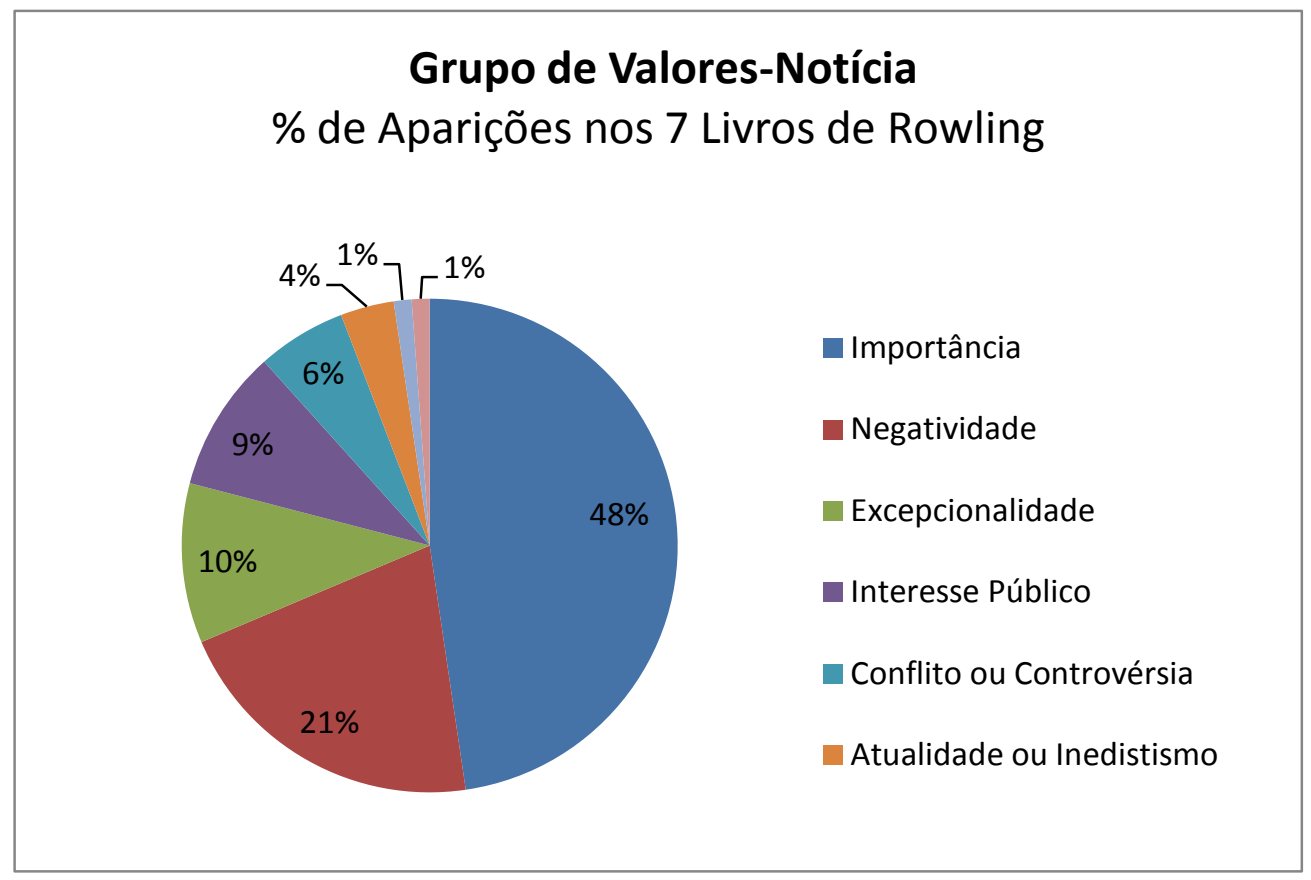

Gráfico 1: Grupo de valores-notícia. Fonte: autoria própria

\section{Importância}

O grupo composto pela importância - seja esta do acontecimento em si, de sua consequência, de sua pertinência para a sociedade, ou por causa dos agentes de notoriedade envolvidos - é o critério de noticiabilidade que se apresenta com maior repetitividade na imprensa de Harry Potter, com 41 aparições (48\%). Combinando-se com questões de amplitude e o impacto do acontecimento no leitor, assim como sua intensidade e gravidade, a importância não permeia o jornalismo nos sete livros, mas aparece com maior frequência nas obras em que a imprensa tem maior relevância para a história - Harry Potter e o Cálice de Fogo e Harry Potter e a Ordem da Fênix. Deve-se observar que há notícias que se enquadram no grupo da importância tanto pelo acontecimento que relata, quanto pelos agentes de notoriedade envolvidos neste, além de sua consequência e pertinência para a sociedade. 
Pensando-se no âmbito da importância, é possível observar que esta aparece mais vezes ao longo da história pelo agente de notoriedade envolvido no acontecimento. Das 41 notícias e falas de personagens que refletem o valor de importância, 30 têm a questão preponderante de um agente de notoriedade, sendo os principais deles Harry Potter, uma lenda no mundo bruxo, seu arqui-inimigo, Voldemort, e Sirius Black, um notório fugitivo.

"Uma foto colorida de Harry iniciava uma pequena matéria intitulada A MÀGOA SECRETA DE HARRY POTTER. Um menino como nenhum outro - mas sofrendo os problemas típicos da adolescência, escreve Rita Skeeter"8(ROWLING, 2001, p.445, itálico autora, tradução nossa)

"BLACK AINDA DESAPARECIDO. Sirius Black, possivelmente o prisioneiro mais infame a ficar preso na fortaleza de Azkaban, continua evitando captura, como confirmou hoje o Ministério da Magia"9 (ROWLING, 2000, p.33, tradução nossa).

Pode-se observar também a notoriedade de artistas, como atores e membros de bandas, que aparecem em notícias de fofocas. Vale observar que há instituições, como o Ministério da Magia e Hogwarts, que também se tornam agentes de notoriedade pela sua posição e relevância na comunicada mágica. Funcionários do Ministério da Magia, por sua posição de poder, também elevam a importância de acontecimentos por estarem envolvidos nestes. A importância do acontecimento em si, combinada com sua amplitude, impacto, gravidade e intensidade, também aparecem de forma expressiva.

Vale notar que é neste grupo de valores-notícia que se pode perceber a compreensão dos personagens sobre os critérios de noticiabilidade, pela capacidade de discernir o que é ou não importante para se tornar notícia. O critério de noticiabilidade de importância aparece também na fala dos personagens, que, por exemplo, compreendem a diferença que o envolvimento de um agente de notoriedade em um acontecimento tem para a construção da notícia.

\footnotetext{
${ }^{8}$ No original: “A colour photograph of Harry headed a short piece entitled HARRY POTTER'S SECRET HEARTACHE. A boy like no other perhaps - yet a boy suffering all the usual adolescence, writes Rita Skeeter".

${ }^{9}$ No original: BLACK STILL AT LARGE. Sirius Black, possibly the most infamous prisoner ever to be held in Azkaban fortress, is still eluding capture, the Ministry of Magic confirmed today"
} 
"Vai mudar o mundo, este relatório vai', disse Ron. 'Primeira página do Profeta Diário, eu espero, vazamento de caldeirões. "10 (ROWLING, 2001, p.53, tradução nossa).

“'Grande sorriso, Harry', disse Lockhart, através de seus dentes brilhantes. 'Juntos, você e eu valemos a primeira página"'11 (ROWLING, 2004, p.70, tradução nossa).

\section{Negatividade}

O valor-notícia do grupo da negatividade aparece 18 vezes nos livros do Harry Potter (21\%). A infração e a ilegalidade aparecem recorrentemente, através de crimes, prisões, inquéritos e casos de corrupção que se tornam notícias. Os erros, no sentido de falha, também aparecem no âmbito da negatividade: o Profeta Diário reporta erros cometidos pelo Ministério da Magia e seus funcionários, tornando estes inclusive manchetes.

\footnotetext{
"NOVIDADES DA INVASÃO DE GRINGOTTS. Investigações continuam sobre a invasão em Gringotts em 31 de julho, que acreditase ser um trabalho de bruxos ou bruxas do mau ainda desconhecidos"12 (ROWLING, 1998, p.141, tradução nossa).

"MAIS ERROS NO MINISTÉRIO DA MAGIA"13 (ROWLING, 2001, p.179, tradução nossa).
}

É nestas notícias em que o critério da negatividade é preponderante e os erros do Ministério são publicados que a presença do jornalista é inserida de forma clara na história. A percepção dos personagens de Rita Skeeter é construída através das matérias que ela escreve para o Profeta Diário. Quando Skeeter destaca em suas notícias as falhas do Ministério, seus funcionários consideram que a jornalista decide focar e exagerar os supostos erros do governo, ao invés do acontecimento em si. Os funcionários do Ministério não são estranhos a Skeeter e seu trabalho para o Profeta Diário e acabam se

\footnotetext{
${ }^{10}$ No original: “"That'll change the world, that report Will', said Ron. 'Front page of the Daily Prophet, I expect, cauldron leaks."”.

${ }^{11}$ No original: "'Nice big smile, Harry', said Lockhart, through his gleaming own teeth. 'Together, you and I are worth the front page"”.

${ }^{12}$ No original: "GRINGOTTS BREAK-IN LATEST. Investigations continue into the break-in at Gringotts on 31 July, widely believed to be the work of Dark wizards or witches unkown"

${ }^{13}$ No original: "FURTHER MISTAKES AT THE MINISTRY OF MAGIC".
} 


\section{ecot DiAno}

tornando vigilantes de si mesmos, pois sabem que qualquer descuido que cometerem poderá se tornar uma notícia.

\section{Excepcionalidade}

Há nove casos nos quais a excepcionalidade é o critério primário (10\%). O incomum e o inesperado aparecem em notícias nas quais o mundo Trouxa e o mundo mágico colidem e há uma intersecção entre ambas as realidades. No âmbito deste critério, tem-se também notícias que apresentam o extraordinário, o sensacional e a surpresa, além do acidente que representa o fator de imprevisibilidade.

"E, finalmente, observadores de pássaros em todo o lugar reportaram que as corujas do país tem se comportado de uma forma incomum hoje. [...] Especialistas são incapazes de explicar por que as corujas de repente mudaram seu comportamento". O apresentador se permitiu um sorriso." ${ }^{14}$ (ROWLING, 1998, p.6, tradução nossa).

"[...] uma entrevista com um bruxo que dizia ter voado até a lua em uma Cleansweep Six e trazido de volta um saco de sapos da lua para provar [...]"15 (ROWLING, 2003, p. 193, tradução nossa).

\section{Interesse Público}

Há, nos livros de Rowling, oito notícias (9\%) criadas pela autora que podemos considerar que correspondem ao interesse de toda a sociedade, ao bem público e ao seu direito a informação. Todas são criadas no momento em que se tem uma crise na comunidade mágica, a volta de Voldemort, que ameaça a sua estabilidade e enfraquece seu governo. Ao ter domínio deste jornal, Voldemort é capaz de regular tudo aquilo que será dito para a população e o que esta ficará sabendo sobre determinados acontecimentos. Desaparecimentos e mortes daqueles que lutavam contra Voldemort e

\footnotetext{
${ }^{14}$ No original: ““'And finally, bird-watchers everywhere have reported that the nation's owl have been behaving very unusually today. [...] Experts are unable to explain why the owls have suddenly changed their sleeping pattern." The newscaster allow himself a grin"”.

${ }^{15}$ No original: "[...] an interview with a wizard who claimed to have flown to the moon on a Cleansweep Six and brought back a bag of moon frogs to prove it; $[\ldots]$ ”.
} 
buscavam impedir que ele assumisse o poder foram, por exemplo, omitidos ou manipulados.

"HARRY POTTER FINALMENTE FALA: A VERDADE SOBRE AQUELE-QUE-NÃO-DEVE-SER-NOMEADO E A NOITE EM QUE VI ELE VOLTAR" "16 (ROWLING, 2003, p.579, tradução nossa).

“"“Registro de Nascidos-Trouxas”,' ela leu em voz alta. “"O Ministério da Magia iniciou uma pesquisa dos tipos 'NascidosTrouxas', para melhor compreender como eles vieram a possuir os segredos da magia [...]"17 (ROWLING, 2007, p.172, tradução nossa).

Deve-se lembrar que outras notícias criadas nos livros também podem dizer respeito ao interesse público, mas são compostas com outros critérios que se sobrepõem a este. Tem-se como exemplo a notícia sobre a fuga em massa de Azkaban, que pode ser pensada tanto no âmbito da importância, quanto do interesse público. Neste caso, o critério de importância se sobrepõe, pois se tem a relevância acontecimento em si, combinada com seu impacto na sociedade, sua gravidade - vários escaparam -, sua pertinência e sua consequência para a comunidade mágica.

\section{Conflito ou Controvérsia}

O grupo composto pelo conflito ou pela controvérsia, que indicam polêmica, ambiguidade e tensão, pode ser percebido em cinco notícias criadas por Rowling (6\%). O Pasquim, que traz duas das cinco notícias que correspondem a este critério, busca mostrar possibilidades diferentes para uma história, diferentes lados. A revista polemiza assuntos marcantes na comunidade mágica ao mostrar outro lado possível para este, acreditando que esta pode ser também uma verdade que o público merece saber. As outras três notícias são apresentadas no Profeta Diário, com o conflito como elemento predominante.

\footnotetext{
${ }^{16}$ No original: "HARRY POTTER SPEAKS OUT AT LAST: THE TRUTH ABOUT HE-WHO-MUSTNOT-BE-NAMED AND THE NIGHT I SAW HIM RETURN."

${ }^{17}$ No original: “'“Muggle-born Register",' she read aloud. "'The Ministry of Magic is undertaking a survey of so-called 'Muggle-borns', the better to understand how they came to possess magical secrets. $[\ldots] "$
} 
FINALMENTE

A

VERDADE?"18

(ROWLING, 2007, p.25, tradução nossa).

“HARRY POTTER: O ESCOLHIDO?"19 (ROWLING, 2005, p.39, tradução nossa).

\section{Atualidade ou ineditismo}

A atualidade e o ineditismo, relacionados à novidade e à exclusividade, compõem o grupo de critérios de noticiabilidade que mais coexistem com outros valores nas notícias. Em sua maioria, as notícias criadas por J.K Rowling podem ser pensadas no sentido de novidade, de um acontecimento recente, como é o caso das informações publicadas no Profeta Diário que se referem às cenas de terror na Copa do Mundo de Quadribol e as noticiadas na Televisão Trouxa sobre o comportamento não usual das corujas durante o dia. Enquanto a primeira é pensada principalmente no âmbito da importância e a segunda da excepcionalidade, o quesito de novidade está presente nas duas. Há notícias, entretanto, em que o ineditismo se sobrepõe a outros critérios de noticiabilidade. Em três casos (4\%) o jornal Profeta Diário deixa claro a exclusividade da notícia, explicita que eles são o único veículo a publicar estas informações.

"EXTRATO EXCLUSIVO DA NOVA BIOGRAFIA DE ALBUS DUMBLEDORE de Rita Skeeter"20 (ROWLING, 2007, p.178, itálico da autora, tradução nossa).

“O ENORME ERRO DE DUMBLEDORE. [...] Se isso não fosse suficiente, o Profeta Diário agora descobriu evidências de que Hagrid não é - como ele sempre fingiu - um bruxo de puro-sangue. Ele não é, na verdade, nem puro humano. Sua mãe, como podemos exclusivamente revelar, é ninguém mais que a giganta Fridwulfa, cujo paradeiro é atualmente desconhecido". ${ }^{21}$ (ROWLING, 2001, p. 380-382, itálico da autora, tradução nossa).

\footnotetext{
${ }^{18}$ No original: "DUMBLEDORE - THE TRUTH AT LAST?".

${ }^{19}$ No original: "HARRY POTTER: THE CHOSEN ONE?"

${ }^{20}$ No original: "EXCLUSIVE EXTRACT FROM THE UPCOMING BIOGRAPHY OF ALBUS DUMBLEDORE by Rita Skeeter".

${ }^{21}$ No original: "DUMBLEDORE'S GIANT MISTAKE. [...] As if this were not enough, the Daily Prophet has now unearthed evidence that Hagrid is not - as he has always pretended - a pure-blood wizard. He is not, in fact, even pure human. His mother, we can exclusively reveal, is none other than the giantess Fridwulfa, whose whereabouts are currently unknown.".
} 


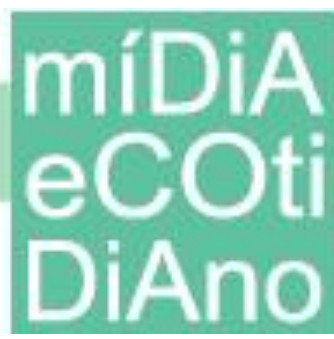

\section{Emoção, suspense ou entretenimento}

O grupo composto pela emoção, suspense e entretenimento aparece apenas uma vez ao longo dos livros de Rowling. A notícia que diz respeito unicamente a este valor é publicada no Pasquim: "SEGREDOS DAS RUNAS ANTIGAS REVELADAS"22 (ROWLING, 2003, p.190, tradução nossa). Com uma chamada impactante e um formato criativo que exige que o leitor vire de cabeça para baixo a revista para descobrir os segredos das runas antigas, a notícia torna-se parte deste grupo.

\section{Proximidade}

A proximidade aparece apenas uma vez na história de Harry Potter. Em uma notícia veiculada na televisão Trouxa, vê-se, pelo comentário de seu espectador, o tio Vernon, a implicação de uma proximidade geográfica: "[...] Notícias de seca no Sudeste ("Espero que o vizinho esteja ouvindo!" gritou tio Vernon, "com seus sprinkles ligados as três da manhã" [...]"23 (ROWLING, 2003, p.4, tradução nossa, grifos nossos). A notícia diz respeito à seca na região em que esta é veiculada.

\section{A função social da imprensa em Harry Potter}

Do primeiro ao último livro da série escrita por Rowling, tem-se a imprensa como uma personagem do cotidiano. É possível observar por diversas vezes no enredo o hábito de acompanhar os meios de comunicação: as pessoas tomam café e leem o jornal, sentam de noite para assistir o noticiário, sempre acompanham as matérias de uma revista e ouvem o rádio enquanto cozinham, por exemplo. A imprensa é uma parte do dia a dia da vida dos personagens e se insere naturalmente no enredo, tornando-se importante para a história ao assumir uma função básica: informar (BOND, 1959; BELTRÃO, 1980; CORNU, 1994; TRAQUINA, 2002).

O desejo de estar informado perpassa toda a série de livros do Harry Potter. É reiterante a ideia de que o público sabe o que está acontecendo por causa da imprensa e que quem não acompanha os meios de comunicação não se atualiza sobre principais

\footnotetext{
22 No original: "SECRETS OF THE ANCIENT RUNES REVEALED”.

${ }^{23}$ No original: “[...] news of drought in the Southeast ("I hope he's listening next door!" bellowed Uncle Vernon, "with his sprinklers on at three in the morning") [...]".
} 


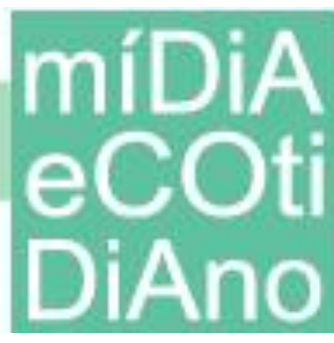

acontecimentos. Aquilo que não é divulgado na imprensa dificilmente chegará ao público e, se chegar, apresenta-se como rumor, pois não foi comunicado na imprensa.

\section{Informar o que está acontecendo no cotidiano}

O Profeta Diário, o principal veículo informativo dos bruxos, é central no papel de informar da imprensa. Os personagens reconhecem que é através do jornal que eles - e o público em geral - são capazes de saber o que está acontecendo no dia a dia do mundo mágico. Bruxos como Harry e Hermione, que não têm família no mundo da magia, ficariam isolados desta realidade durante as férias se não assinassem o jornal: “[...] tinha uma propaganda no Profeta Diário (Eu assinei o jornal, é muito bom saber o que está acontecendo no mundo bruxo)"24 (ROWLING, 2000, p.14, tradução nossa, itálico da autora). A divisão entre a realidade Trouxa e mágica torna mais forte a necessidade da imprensa para a pessoa ficar informada. Os bruxos que vivem em meio a apenas Trouxas ficariam isolados de sua realidade se não pelos meios de comunicação.

Da mesma forma que as notícias possibilitam ao público conhecimento sobre os acontecimentos, quando os meios de comunicação deixam de publicar informações a sociedade dificilmente conseguia saber destes. Para o público em geral, não há como tomar consciência do que está realmente acontecendo quando a imprensa não diz nenhuma palavra sobre determinados fatos. Rumores podem existir ao serem iniciados por quem presenciou o acontecimento, mas no momento em que estes não são confirmados pela imprensa, acabam sendo esquecidos ou desacreditados. Isso demonstra como é necessária a existência da imprensa para informar a sociedade sobre o que está acontecendo no mundo.

\section{Ditar os assuntos que as pessoas vão falar}

A imprensa se torna parte da rotina dos personagens. Vernon Dursley, por exemplo, tinha o hábito de acompanhar a imprensa Trouxa diariamente: no café da manhã lia o jornal e a noite assistia o noticiário na televisão. Ao longo de todos os livros este costume do personagem fica claro e se torna uma forma de caracterizá-lo. Em

\footnotetext{
${ }^{24}$ No original: “[...] there was an advertisement in the Daily Prophet (I've been getting it delivered, it's so good to keep up with what's going on in the wizarding world)".
} 


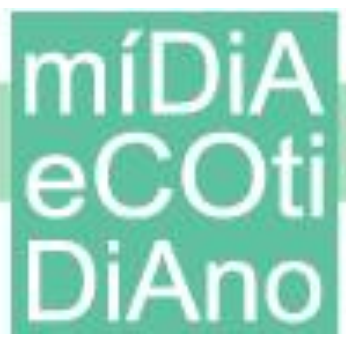

Hogwarts, no horário do café da manhã, milhares de corujas entravam no Grande Salão e distribuíam para os alunos jornais, revistas e cartas que vinham de casa com notícias. $\mathrm{O}$ que era publicado na imprensa era o que as pessoas sabiam sobre os assuntos. As conversas passavam a ser relacionadas aos acontecimentos que eram divulgados na imprensa, tanto no âmbito do mundo Trouxa, como no âmbito do mundo bruxo.

As novidades de um caso importante como a fuga de Black eram acompanhadas e discutidas incansavelmente pelas pessoas do mundo bruxo. O caso Black foi tão relevante que foi anunciado na imprensa Trouxa e acabou sendo discutido também por aqueles que não sabiam sequer de onde o prisioneiro havia escapado ou porque ele estava preso: “'Ouviu a notícia hoje de manhã, Marge? Sobre o prisioneiro que fugiu?""25 (ROWLING, 2000, p. 24, tradução nossa).

\section{Conferir credibilidade e prestígio a pessoas, objetos e instituições}

Nos livros da série Harry Potter a imprensa possui também a capacidade de conferir credibilidade e prestígio a pessoas, instituições e até objetos. Os personagens têm nos meios de comunicação uma referência para estabelecer aquilo que é importante, bom, ou confiável, isto é, eles acreditam no que é dito pelo jornalismo para formularem suas opiniões e fazerem suas escolhas. Ao escolher uma vassoura para jogar Quadribol, por exemplo, os personagens buscam as avaliações e os comentários sobre estas nos meios de comunicação para decidir qual é a melhor vassoura para ser comprada. O professor Lockhart, obcecado pela fama, não perde oportunidades de sair na imprensa, pois sabe o reconhecimento que isto lhe dá perante o público. Para ele, um grande fator que indica sua importância e que lhe dá prestígio entre os bruxos é o fato de ter sido escolhido cinco vezes seguidas o sorriso mais charmoso pela revista Witch Weekly.

Os jornalistas, no momento em que se apresentam como tais, membros de um meio de comunicação, ganham também prestígio e credibilidade perante o público. Ao dizer que é um repórter do Profeta Diário, por exemplo, o personagem já assume perante os outros uma superioridade, no sentido de estar ali representando um importante meio de comunicação que será responsável por notícias lidas por milhares de

\footnotetext{
${ }^{25}$ No original: "“Heard the news this morning, Marge? What about that escaped prisoner, eh?"”.
} 


\section{míDiA

pessoas. O personagem também recebe a confiança de quem conversa, uma vez que assume a figura de um defensor da verdade, que relata os fatos para toda a sociedade tomar conhecimento.

\section{Visto e Imprevisto: cruzamento da análise}

Encontramos na literatura um espaço de interpretação dos diversos elementos que compõem nossa realidade. A representação de Rowling do jornalismo e dos jornalistas permite um olhar do imaginário criado em volta da profissão. Sabemos muito pouco dos acontecimentos sem os meios de comunicação e, por isso, precisamos deles para ficarmos informados sobre os fatos, o que justifica a existência do jornalismo como uma instituição especializada em transmitir informações.

Pensando-se no panorama do enredo de Harry Potter, o jornalismo responde à mesma necessidade de informar: "Tem saído por todo o Profeta Diário, mas eu não acho que você receba isso com os Trouxas"26 (ROWLING, 1998, p.107). Harry, enquanto isolado do mundo bruxo e sem uma assinatura do Profeta Diário, não tem como conhecer os fatos da realidade mágica. Ele precisa dos meios de comunicação bruxos ou de contato com pessoas que tenham acesso a estes meios para descobrir os acontecimentos do mundo mágico. O jornalismo, através de todos os veículos apresentados no livro, corresponde à necessidade de informação dos personagens, que precisam dos meios para saber o que está acontecendo.

Em Harry Potter a imprensa precisa diariamente selecionar acontecimentos e escrever notícias para serem divulgadas para seu público. Percebe-se que os critérios de noticiabilidade, isto é, valores que auxiliam tanto na escolha do acontecimento, quanto na elaboração da notícia, estão presentes em todos os meios de comunicação do enredo de Rowling, independentemente da situação corrente do mundo bruxo. Mesmo quando a imprensa cumpre a função de informar apesar da pressão do governo e dos interesses pessoais dos jornalistas no processo de construção da notícia, os critérios de noticiabilidade continuam como fatores essenciais para o processo jornalístico.

\footnotetext{
${ }^{26}$ No original: It's been all over the Daily Prophet, but I don't suppose you get that with the Muggles.
} 


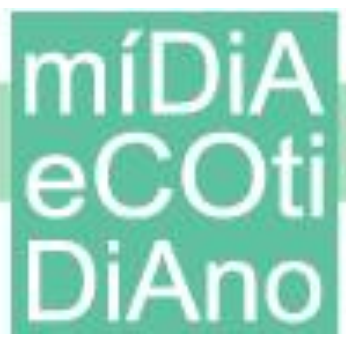

Na medida em que assume o papel de informar, o jornalismo ganha um poder de fala na sociedade. Os meios de comunicação, de acordo com Miguel (1999), elegem temas, apresentam seus fatos relevantes e auxiliam no estabelecimento de valores, além de produzirem crédito social ao permitirem que alguns indivíduos ocupem posições de autoridade em determinados campos. O jornalismo, ao agregar e difundir a informação, assume uma posição na qual é capaz de conferir credibilidade e prestígio. Em Harry Potter, os personagens têm os meios de comunicação como referência para seu cotidiano, ao utilizá-los para decidir de que forma agir, se devem ou não adquirir um produto ou se devem ou não se comportar de certa maneira.

Nos livros, o jornalismo assume uma dupla e contraditória imagem, como traz Travancas (2003). Em diferentes momentos da história, os veículos aparecem tanto como uma forma de trazer a verdade para as pessoas, quanto como um meio de manipulação de informações. A diferença irá perpassar pela forma como é feita a seleção dos acontecimentos e da construção das notícias. Quando a imprensa sofre a censura do governo, ela deixa de ser capaz de noticiar todos e quaisquer fatos de interesse público e sua função de informar passa a ser prejudicada. Os jornalistas e sua responsabilidade ao noticiar um acontecimento também influenciam a forma como o jornalismo é percebido ao longo dos livros.

Enquanto a ideia de que o jornalismo tem um dever com a verdade é aparente em Harry Potter, também se destaca na obra que os meios de comunicação falham inúmeras vezes em sua função social, pois não conseguem cumprir esta exigência da profissão. A pressão do governo sob os veículos é clara ao longo da história de Rowling e impede inúmeras vezes que o jornalismo seja feito sob o imperativo de verdade. Quando forte e estável, o governo consegue influenciar aquilo que é publicado:

'O Profeta Diário não disse uma palavra sobre ele morrer, ou sobre encontrar seu corpo,' Bill continuou. 'Mas isso não significa muito. Tem mantido muita coisa quieta esses dias' ${ }^{27}$ (ROWLING, 2007, p.80, tradução nossa).

\footnotetext{
${ }^{27}$ No original: “'The Daily Prophet hasn't said a word about him dying, or about finding the body,' Bill went on. 'But that doesn't mean much. It's keeping a lot quiet these days.",
} 
'[...] Não me importa o que Fudge continua dizendo para o Profeta Diário, estamos tão perto de capturar Black quanto de inventar varinhas que façam feitiços sozinha' ${ }^{28}$ (ROWLING, 2000, p.53, tradução nossa).

A competência dos jornalistas seria, como explica Traquina (2008), o fornecimento de informações à sociedade. Forma-se envolto na profissão o mito do furo jornalístico e do jornalismo como grande aventura na qual se busca a verdade. Rita Skeeter e Xenophilius Lovegood, que assumem a função de jornalistas, incorporam, em diferentes momentos da história, estes mitos, além de corporificar os estereótipos destes profissionais na ficção trazidos por Travancas (2003).

Ao ser inserida no enredo, Skeeter assume o papel de uma jornalista inescrupulosa que faz qualquer coisa por uma grande história. Fica claro ao longo da história que Skeeter manipula os fatos de forma que se encaixem na notícia que ela imaginou e que lhe daria maior ibope. Ela, a partir de suas histórias desarticuladas da verdade, dá início ao processo no qual o Profeta Diário deixa de se tornar unânime perante a sociedade como um veículo que publica informações credíveis, o que é um tensionamento já que a credibilidade é o capital do campo jornalístico e ela será maior conforme mais “expedientes do real" a imprensa apresentar (BERGER, 2003, p. 11).

Skeeter acredita que, como jornalista, é seu dever se manter sempre envolta do Ministério, vigiando o governo e seus funcionários. A jornalista justifica sua diligência quanto aos processos do Ministério pelo dever que esta tem com seus leitores: "Nossos leitores têm o direito de saber a verdade [...]"29 (ROWLING, 2001, p.391, tradução nossa). O direito do público à verdade, defendido por Skeeter, relaciona-se a ideia do jornalismo como Quarto Poder, o cão de guarda da sociedade, defensor do interesse público (TRAQUINA, 2008). Skeeter olha para as notícias como uma forma de ganhar visibilidade perante o público. Ela está sempre em busca de novidades para instigar a curiosidade público e formas de transformar suas notícias em matérias de destaque e relevância entre a comunidade bruxa.

\footnotetext{
${ }^{28}$ No original: “[...] I don't care what Fudge keeps telling, the Daily Prophet, we're no nearer catching Black than inventing self-spelling wands.".

${ }^{29}$ No original: "Our readers have the right to know the truth [...]".
} 
Lovegood se coloca como a antítese de Skeeter. Como dono da revista O Pasquim, o jornalista é percebido como um repórter sem credibilidade, incapaz de noticiar a verdade, mas que se compromete com suas convicções de abrir na revista um espaço para matérias alternativas. Com a mudança de contexto do mundo mágico, a posição dos veículos e dos jornalistas é alterada. Lovegood se torna referência do jornalismo comprometido com a verdade, que luta para manter o público informado.

Inicialmente o Profeta Diário e a revista Witch Weekly assumiam um lugar de fala de grande importância na sociedade mágica: eram referência para uma informação correta, precisa e coerente com a realidade. Skeeter, com suas grandes histórias que correspondiam ao desejo de informação e verdade do público, tinha grande destaque na sociedade. Por outro lado, O Pasquim era visto como espaço para bobagens e matérias infundadas.

A credibilidade sustenta os meios de comunicação como empresas e diferencia um do outro, se apresentando como reflexo de um jornalismo de qualidade produzido ao longo do tempo. Só se mantém a credibilidade à medida que se mantém o comprometimento com a verdade em suas notícias (CHRISTOFOLETTI, 2008). Como coloca Charaudeau (2007), contudo, os meios são partes interessadas na prática de informar, a medida que se instituem como uma empresa de fabricar informações. Em um mercado de concorrência, elas buscam maneiras de se diferenciar umas das outras e acionam estratégias para narrar os acontecimentos que os destaquem dos outros veículos (CHARAUDEAU, 2007). Em Harry Potter, o Profeta Diário, principal veículo da comunidade bruxa, elucida o interesse econômico dos meios de comunicação: "Então o Profeta Diário existe para dizer as pessoas o que elas querem ouvir, é isso?” [...] “O Profeta existe para se vender, menina boba"30 (ROWLING, 2003, 567, tradução nossa).

O Profeta Diário e a Witch Weekly perdem diversos leitores à medida que deixam de informar acontecimentos que o público considera relevante e começam a atacar pessoas carismáticas que os bruxos adoram. Skeeter representa esta mudança, incorporando todas as características do jornalista vilão descritos por Travancas (2003), no momento em que passa a inventar e aumentar histórias para ganhar audiência e fama.

\footnotetext{
${ }^{30}$ No original: "So the Daily Prophet exists to tell people what they want to hear, does it?" [...] "The Prophet exists to sell itself, you silly girl".
} 


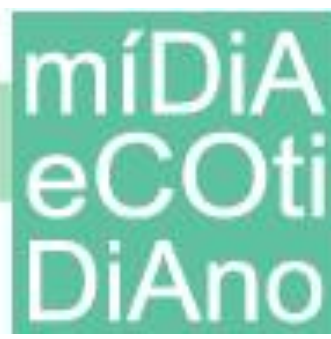

Enquanto isto, O Pasquim abre espaço para os fatos ignorados pelos outros dois veículos e assume um espaço de fala no qual se torna referência para "verdade" e coerência com a realidade. Lovegood passa a ser respeitado e se torna um modelo de credibilidade para a sociedade.

É importante considerar que adesão do leitor ao jornalismo não é estável: ela varia em graus e deve ser constantemente reafirmada. Cada pessoa escolhe ou não renovar o vínculo com o meio de comunicação, por isso ter a confiança do público em seu processo de escolha dos acontecimentos e elaboração é essencial. Assim, "a eficácia do jornalismo depende de seu reconhecimento, pelo leitor, como um discurso credível” (BENETTI; REGINATO, 2013, p. 13).

\section{CONCLUSÃO}

As pessoas sempre buscaram formas de dar sentido aos acontecimentos de seu cotidiano. Com a crescente complexidade do mundo, tornam-se cada vez mais importantes estes espaços que os homens utilizam para conseguir compreender os diversos fatores que compõem seu dia a dia. Tanto o jornalismo quanto a literatura são capazes de assumir esta função, tornando-se formas de conhecimento sobre o mundo, assumindo papéis de organizar a aleatoriedade do mundo e auxiliar a sociedade na compreensão de sua realidade. Enquanto os meios de comunicação correspondem à necessidade de informação sobre os acontecimentos do mundo, os livros de ficção mostram-se como formas de interpretação da realidade através das construções de personagens e instituições por seus autores.

Buscamos neste trabalho analisar os critérios de noticiabilidade e a função social da imprensa na série de livros Harry Potter. Ao identificar personagens e instituições que exercem papéis ligados à imprensa percebemos que estes incorporam os mitos e os estereótipos criados no imaginário do jornalismo. Ao mapearmos os critérios de noticiabilidade utilizados pelo jornalismo na série de livros foi possível observar que eles se assemelham àqueles identificados por Moreira (2006) em sua dissertação de mestrado em que estudou os valores-notícia no jornalismo impresso dos jornais Folha 


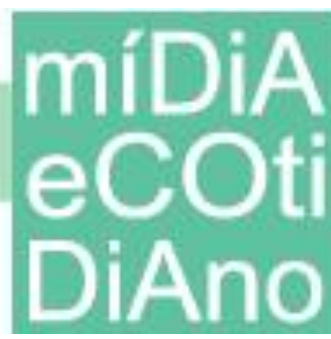

de São Paulo, O Estado de São Paulo e O Globo. Encontramos na série 86 articulações dos valores-notícia na imprensa de Harry Potter, considerando tanto os veículos Trouxas quanto bruxos, divididos em oito grupos de critérios de noticiabilidade. Os valores contemplados foram de importância; emoção, suspense ou entretenimento; excepcionalidade; conflito ou controvérsia; negatividade; atualidade ou ineditismo; proximidade; e interesse público.

Compreendemos ainda o papel social exercido pela imprensa através de sua função de informar, uma vez que os meios de comunicação se tornam essenciais na série de livros do Harry Potter para que os personagens mantenham a conexão com o mundo bruxo e seus acontecimentos. Sistematizamos a partir dos sete livros de Rowling três papéis sociais assumidos pela imprensa: informar o que está acontecendo no cotidiano, ditar os assuntos que as pessoas vão falar e conferir credibilidade e prestígio para pessoas, objetos e instituições. Por assumir estas funções sociais o jornalismo se coloca no lugar de uma instituição que organiza a experiência de mundo das pessoas. Cria-se uma relação de confiança entre o público e os meios de comunicação: acreditase que a imprensa irá contar a verdade.

Quando os personagens buscam os veículos jornalísticos querem um relato da realidade, querem conhecer o que está acontecendo no mundo e confiam na imprensa para lhes proporcionar isto sem a distorção dos fatos. Forma-se uma relação entre o público e o jornalismo, na qual o primeiro tem a escolha de renovar o vínculo que forma com a imprensa. Isto é, cada pessoa, ao ler o jornal, por exemplo, pode escolher fazê-lo novamente no dia seguinte ou não. $\mathrm{O}$ jornalismo se torna parte da rotina das pessoas e os acontecimentos jornalísticos, como aponta Benetti (2010), ajudam a definir historicamente uma sociedade porque o seu próprio processo de produção está imbuído de valores que circulam nesta mesma sociedade.

\section{REFERÊNCIAS}

ALSINA, Miquel Rodrigo. A Construção da Notícia. Petrópolis (RJ): Editora Vozes, 2009.

BARDIN, Laurence. Análise de Conteúdo. São Paulo: Edições 70, 2006. 


\section{míDiA

BELTRÃO, Luiz. Jornalismo interpretativo: filosofia e técnica. 2. ed. Porto Alegre: Sulina, 1980.

BENETTI, Marcia. O jornalismo como gênero discursivo. Galáxia. N. 14. São Paulo: PUC-SP, 2008.

O jornalismo como acontecimento. In: BENETTI, Marcia; FONSECA, Virginia Pradelina da Silveira (Org). Jornalismo e Acontecimento - Volume 1. Florianópolis: Insular, 2010.

BENETTI, Marcia; REGINATO, Gisele. A adesão do leitor ao contrato de comunicação proposto pelo jornalismo: estudo da revista Veja no Facebook. In: XI Encontro Nacional de Pesquisadores em Jornalismo. Anais... Brasília: SBPJor, 2013.

BERGER, Christa. Campos em confronto: a terra e o texto. 2. ed. Porto Alegre: Editora da UFRGS, 2003.

BOND, Fraser. Introdução ao jornalismo. Rio de Janeiro: Agir, 1959.

BUCCI, Eugênio. Sobre ética e imprensa. São Paulo: Cia. das Letras, 2000.

CHARAUDEAU, Patrick. Discurso das mídias. São Paulo: Contexto, 2007.

CHRISTOFOLETTI, Rogério. Ética no jornalismo. São Paulo: Contexto, 2008.

CORNU, Daniel. Jornalismo e Verdade. Lisboa: Instituto Piaget, 1994.

FRANCISCATO, Carlos Eduardo. A Fabricação do Presente. São Cristóvão: Ed. UFS, 2005.

GOMIS, Lorenzo. Teoria del periodismo. Cómo se forma el presente. Barcelona: Paidós, 1997.

HERSCOVITZ, Heloiza Golpspan. Análise de conteúdo em jornalismo. In: LAGO, Cláudia; BENETTI, Marcia (Org). Metodologia de Pesquisa em Jornalismo. Petrópolis (RJ): Vozes, 2008.

KOVACH; Bill; ROSENSTIEL, Tom. Os elementos do jornalismo: o que os profissionais do jornalismo devem saber e o público deve exigir. Porto: Porto Editora, 2004.

LAGO, Cláudia. De romântico e de louco... reflexões sobre o romantismo jornalístico. Anais do XII Encontro Anual da Compós. Recife: UFPE/Compós, 2003. 
MIGUEL, Luis Felipe. O jornalismo como sistema perito. Revista de Sociologia da USP, São Paulo, v. 11, n. 1, 1999.

MOREIRA, Fabiane Barbosa. Os valores-notícia no jornalismo impresso: análise das 'características substantivas' das notícias nos jornais Folha de São Paulo, O Estado de São Paulo e O Globo. Dissertação de mestrado. Porto Alegre: UFRGS, 2006.

MOTTA, Luiz Gonzaga. O Trabalho Simbólico da Notícia. Anais do XI Encontro Anual da COMPÓS. Rio de Janeiro (RJ): Compós, 2002.

NEVEU, Érik. Sociologia do Jornalismo. São Paulo: Loyola, 2006.

RODRIGUES, Adriano Duarte. O acontecimento. In: TRAQUINA, Nelson (org.). Jornalismo: questões, teorias e estórias. Lisboa: Vega, 1993.

ROWLING, J.K. Harry Potter and the Chamber of Secrets. Londres: Bloomsbury, 2004.

. Harry Potter and the Deathly Hallows. Londres: Bloomsbury, 2005.

. Harry Potter and the Goblet of Fire. Londres: Bloomsbury, 2001.

. Harry Potter and the Half-Blood Prince. Nova York: Schoolastic, 2005.

. Harry Potter and the Order of the Phoenix. Nova York: Schoolastic, 2003.

. Harry Potter and the Prisoner of Azkaban. Londres: Bloomsbury, 2000.

. Harry Potter and the Sorcerer's Stone. Nova York: Schoolastic, 1998.

SMITH, Sean. J.K. Rowling. Uma biografia do gênio por trás de Harry Potter. Rio de Janeiro: Sextante, 2003.

TRAQUINA, Nelson. Jornalismo. Lisboa: Quimera, 2002.

Teorias do Jornalismo. A tribo jornalística - uma comunidade interpretativa transnacional. Florianópolis: Insular, 2008.

TRAVANCAS, Isabel. O jornalista e suas representações literárias. Anais do XXVI Congresso Brasileiro de Ciências da Comunicação. Belo Horizonte (MG): INTERCOM, 2003.

WOLF, Mauro. Teorias da Comunicação. Lisboa: Presença, 2006. 